Open Access

\title{
Maternal care in Acanthosomatinae (Insecta: Heteroptera: Acanthosomatidae) - correlated evolution with morphological change
}

\author{
Jing-Fu Tsai ${ }^{1,3^{*}}$, Shin-ichi Kudo ${ }^{2}$ and Kazunori Yoshizawa ${ }^{1}$
}

\begin{abstract}
Background: Maternal care (egg-nymph guarding behavior) has been recorded in some genera of Acanthosomatidae. However, the origin of the maternal care in the family has remained unclear due to the lack of phylogenetic hypotheses. Another reproductive mode is found in non-caring species whose females smear their eggs before leaving them. They possess pairs of complex organs on the abdominal venter called Pendergrast's organ $(\mathrm{PO})$ and spread the secretion of this organ onto each egg with their hind legs, which is supposed to provide a protective function against enemies. Some authors claim that the absence of PO may be associated with the presence of maternal care. No study, however, has tested this hypothesis of a correlated evolution between the two traits.
\end{abstract}

Results: We reconstructed the molecular phylogeny of the subfamily Acanthosomatinae using five genetic markers sequenced from 44 species and one subspecies with and without maternal care. Eight additional species from the other two acanthosomatid subfamilies were included as outgroups. Our results indicated that maternal care has evolved independently at least three times within Acanthosomatinae and once in the outgroup species. Statistical tests for correlated evolution showed that the presence of maternal care is significantly correlated with the secondary loss or reduction of PO. Ancestral state reconstruction for the node of Acanthosoma denticaudum (a non-caring species in which egg smearing with developed POs occurs) and A. firmatum (a caring species with reduced POs) suggested egg smearing was still present in their most recent common ancestor and that maternal care in A. firmatum has evolved relatively recently.

Conclusions: We showed that maternal care is an apomorphic trait that has arisen multiple times from the presence of PO within the subfamily Acanthosomatinae. The acquisition of maternal care is correlated with the reduction or loss of $\mathrm{PO}$, which suggests an evolutionary trade-off between the two traits resulting from physiological costs. This prediction also implies that presence of maternal care can be highly expected for those groups lacking behavioral data, which invariably also lack the organ. No secondary loss of maternal care was detected in the present tree. We suggest that the loss of maternal care may be suppressed due to the vulnerability of the PO-free condition, which thus maintains maternal care.

Keywords: Molecular phylogeny, Acanthosomatinae, Maternal care, Egg guarding, Egg smearing, Pendergrast's organ, Correlated evolution

\footnotetext{
* Correspondence: jingfu.tsai@gmail.com

${ }^{1}$ Systematic Entomology, School of Agriculture, Hokkaido University, Sapporo 060-8589, Japan

${ }^{3}$ Department of Biology, National Museum of Natural Science, Taichung

40427, Taiwan

Full list of author information is available at the end of the article
}

\section{Biomed Central}

(C) 2015 Tsai et al. Open Access This article is distributed under the terms of the Creative Commons Attribution 4.0 International License (http://creativecommons.org/licenses/by/4.0/), which permits unrestricted use, distribution, and reproduction in any medium, provided you give appropriate credit to the original author(s) and the source, provide a link to the Creative Commons license, and indicate if changes were made. The Creative Commons Public Domain Dedication waiver (http://creativecommons.org/publicdomain/zero/1.0/) applies to the data made available in this article, unless otherwise stated. 


\section{Background}

Parental care in insects has been the focus of several studies that examined its adaptive functions with regard to both parents and offspring [1]. Such studies may clarify selection regimes that maintain parental care under current ecological conditions and shape co-adaptive behavioral interactions between parents and offspring. However, the selection acting on current populations may not be the same as that in the origin. The phylogeny-based comparative analysis is a powerful tool for testing or generating the hypotheses about the historical developments of traits. However, relatively few attempts have been made to apply this analysis to the evolution of parental care in insects $[2,3]$.

Evolutionary transitions and the lability of uni- or biparental care have attracted the interest of evolutionary biologists [4-6]. Complex parental care, with integrated morphological (e.g., placenta) and behavioral components, may have a low likelihood of loss. For example, viviparity (a common form of maternal care associated with internal fertilization) has evolved many times, but it has never been lost in ray-finned fish [7]. Parental food provisioning which has been elaborated through co-evolution between parents and their offspring confers resistance to loss [8]. In contrast, simple attendance and guarding of offspring might be more easily lost in low-risk environments than complex parental care [6]. Tallamy and Schaefer [9] suggested that parental care is a plesiomorphic relic in Hemiptera, which has repeatedly been lost due to the high cost of caring.

Post-ovipositional parental care has been recorded in at least 64 genera representing 14 families of four infraorders of heteropteran insects [9-16]. Most of them exhibit maternal care, whereas exclusive paternal care is restricted to four families only with reports of dozens of genera: Belostomatidae, Coreidae, Reduviidae, and Pentatomidae $[15,17,18]$. Approximately $70 \%$ of the species in which maternal care has been documented belongs to the superfamily Pentatomoidea. They have developed diversified strategies of maternal investments, such as physical protection against predators with defensive movements in many taxa (e.g., $[13,19,20])$, brood caring combined with nymphal phoresy in the Phloeidae and Tessaratomidae (e.g., $[11,13,21])$, joint guarding in some Acanthosomatidae (e.g., [22, 23]), or a series of complex cares including egg-translocation, trophic egg production, hatching assistance, progressive provisioning and joint breeding in cydnoid families (e.g., [24-35]).

The family Acanthosomatidae is one of the best known members of Pentatomoidea, in which the females of several species display a simple form of parental care, egg-nymph guarding, with effective resource allocation among eggs [10, 23, 36-43]; for an extensive review see [20]. Most of them are oligo-or polyphagous, arboreal herbivores that feeding on the developing fruits of some conifers and many flowering plants (e.g., [20, 44]). The family currently contains about approximately 285 described species in 56 genera in three subfamilies, namely Acanthosomatinae, Blaudusinae and Ditomotarsinae [45-53]. Considering that its sister group, Lestoniidae, is an endemic Australian family, and that the majority (approximately $80 \%$ ) of acanthosomatid genera is distributed in the fragmented landmasses of Gondwana, the family is very likely of Gondwanan origin. However, the greatest species diversity (nearly $80 \%$ of the total number of species) is found in the 14 genera of the subfamily Acanthosomatinae, with a high species richness in East, South, and Southeast Asia.

Many acanthosomatine species exhibit maternal care. For example, members of the genera Elasmucha and Sastragala attend their eggs and nymphs until the 2nd to 5 th instar [10]. Several studies have identified the strategy's defensive function, the agents of offspring mortality and have quantified its benefits in terms of offspring survival under field conditions [39, 41, 54-58]. In contrast, the females of other species of the subfamily do not show post-ovipositional care, and instead, smear the eggs one after another with secretion from Pendergrast's organ using the hind legs before leaving the clutch [59-61], see also Additional files 1 and 2. The Pendergrast's organ (PO) is a pair of disc-like, depressed, setose areas located sublaterally on the female abdominal sternites V-VII, VIVII or VII, having highly modified cuticle (ductules, pores and setae) with numerous underlying and closely arranged secretory cells in the epidermal layer $[61,62]$. Although no direct experimental evidence has been published thus far, the organ's secretion supposedly functions as a repellent against the predators and parasitoids [61, 63, 64], which can be considered as a form of maternal care if the substances could effectively enhance egg survival.

The monophyly of Acanthosomatidae and its sister relationship with the Lestoniidae are apparently supported by molecular and morphological data $[65,66]$. However, no hypothesis for the phylogenetic relationships within the family has been proposed so far, rendering it difficult to understand the origin and evolution of maternal care. In this study, we focused on the relationships of the subfamily Acanthosomatinae, the taxon containing the largest number of species. We estimated the molecular phylogeny among the major groups of Acanthosomatinae with and without maternal care and incorporated several outgroup representatives of the other two subfamilies using three mitochondrial and two nuclear genes. We evaluated whether the maternal care has a single origin or has evolved independently several times within Acanthosomatidae. We further examined whether the maternal care is associated with morphological changes, i.e., the loss of PO, since some authors have proposed a trend that species showing maternal care lack this organ [60, 61]. 


\section{Results}

Phylogenetic analyses and the clades recovered

The phylogenetic trees resulting from Maximum Likelihood (ML) and Bayesian analyses were nearly identical and were well resolved except for some basal branches (Fig. 1a). The monophyly of the genera Cyphostethus, Elasmostethus and Elasmucha were strongly supported (100\% bootstrap [BP] and posterior probability [PP]) in all analyses. The monophyly of Sastragala was estimated as most likely but this was not robust (77 \% PP). The monophyly of Acanthosoma and Lindbergicoris was not recovered due to a robust sister relationship between $A$. expansum and L. similis (100\% BS and PP). The latter two species never formed a monophyletic group with the rest of Acanthosoma and Lindbergicoris, respectively. The monophyly of Lindbergicoris containing L. gramineus and L. hochii was recovered (100\% BS and PP). The placements of $A$. laevicorne and a clade of the sister species $A$. rufescens $+A$. sichuanense are still inconclusive; the relationships either with the other members of Acanthosoma or Sastragala were weakly supported. A clade consisting of Acanthosoma (excluding A. expansum) and Sastragala is strongly supported (100 \% BS and PP).

The sister relationship between Cyphostethus and Elasmucha was moderately to strongly supported (64 BS and

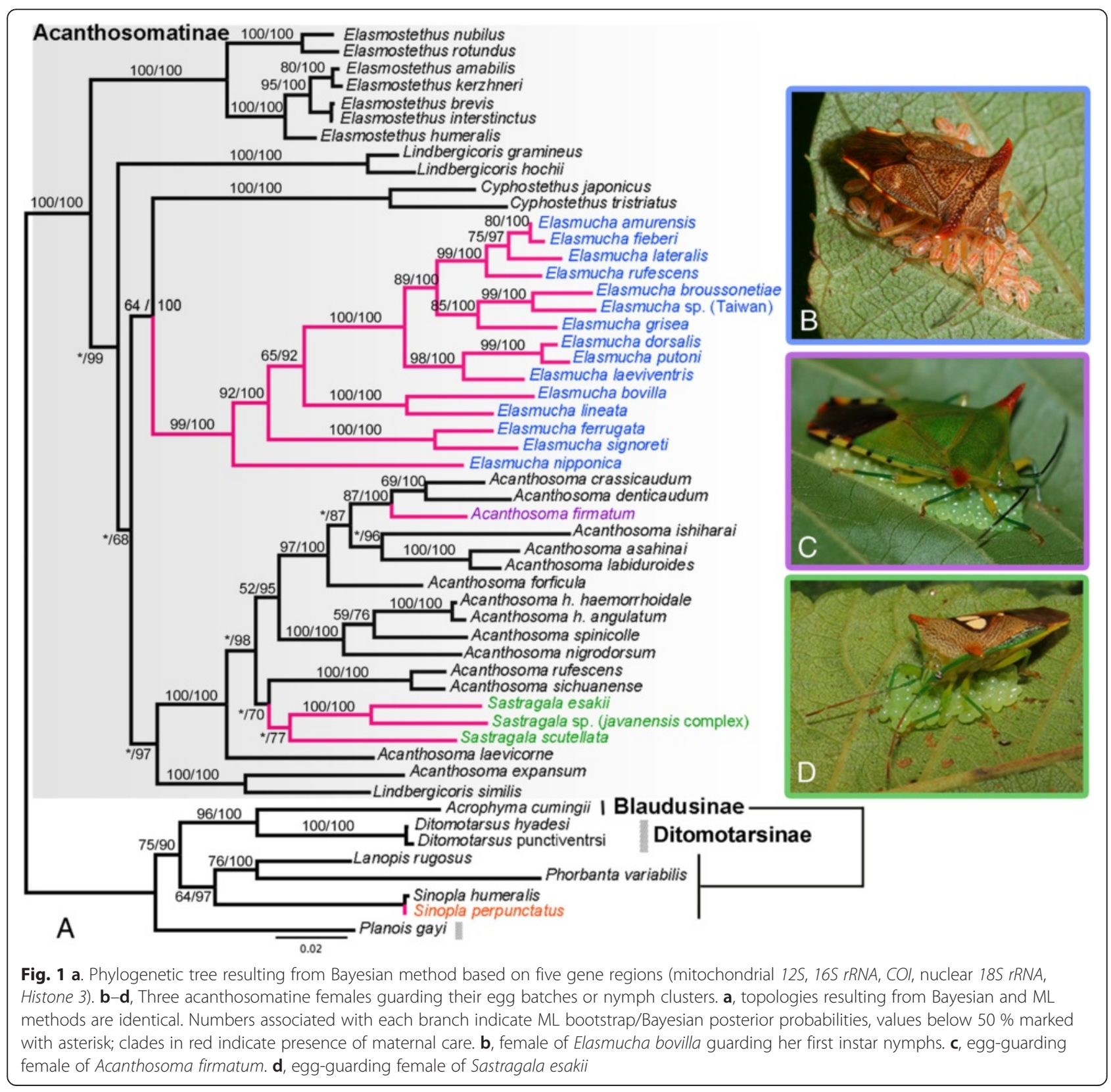


$100 \%$ PP). The internal branches of Elasmucha were well resolved and well supported. Several clades can be recognized in this species-rich genus. The sister relationship between Elasmostethus and the other acanthosomatine genera is supported by the Bayesian method (99 \%) but is weakly supported by ML bootstrapping (27 \%). The internal relationship of Elasmostethus was fully resolved with strong support.

\section{Evolution of maternal care and morphological correlation}

From the resulting tree, three independent origins of maternal care in the subfamily Acanthosomatinae were estimated as most parsimonious: one in the common ancestor of Elasmucha, one in the common ancestor of Sastragala, and one in the species Acanthosoma firmatum (Fig. 1). Shimodaira-Hasegawa and Kishino-Hasegawa tests (constraining all species with maternal care in Acanthosomatinae as a monophyletic group) rejected the monophylgetic origin of the maternal care in the subfamily (Fig. 1a) $(p<0.001$ in both the $\mathrm{SH}$ and $\mathrm{KH}$ tests). At present $A$. firmatum (Walker), frequently referred to in the literature as A. giganteum Matsumura [53], is the only species exhibiting maternal care in the genus Acanthosoma [67]. Similarly, Sinopla perpunctatus in the subfamily Blaudusinae is also the single representative in its genus in which maternal care is known [68].

To understand the correlation between the behavioral and morphological evolution, the character states of PO (which is related to egg smearing) was mapped on the best Bayesian tree (Fig. 2). The correlated evolution analyses [69] demonstrated that the absence of the organ is significantly correlated with the presence of maternal care (actual changes: $p=0.0357$, MINSTATE reconstructedchanges: $p=0.022$, MAXSTATE reconstructed-changes: $p=0.0354$ ). In addition, the difference in likelihood between the independent and dependent model was shown by Pagel's test as significantly greater (difference in likelihood $=12.854, p<0.001$ ). Two characters under any effect factor significantly fit the dependent (= correlated) model better; the independent model was therefore rejected.

Five patterns of PO are shown in Fig. 3, which correspond to the character evolution shown in Fig. 2. In general, species display two pairs of elliptic POs on sternite VI and VII (Fig. 3e, g, h, i), or fused into one large area (Fig. 3b, c), or closely joint (Fig. 3a). In the other examples, species exhibit a pair of large POs on sternite VII (Fig. 3f). Two exceptions are found in A. firmatum and $S$. perpunctatus, in which POs remain but they still exhibit maternal care. However, they frequently have a reduced pair on abdominal sternite VII and have lost one pair on abdominal sternite VI (Fig. 3d, k-l).

The reconstruction of the ancestral state of Pendergrast's organ (PO) performed by likelihood calculation is given in
Fig. 2. The best estimates of the proportional likelihoods for nodes containing maternal care species are as follows: (1) the likelihood for the node of Acanthosoma firmatum and $A$. denticaudum $+A$. crasssicaudum is 0.99 (present) and 0.01 (reduced); (2) the likelihood for the node of Sastragala is 0.22 (present) and 0.78 (absent); (3) the likelihood for the node of Elasmucha is 0.05 (present) and 0.95 (absent); (4) and for the node of Sinopla perpunctatus $+S$. humeralis and Lanopis rugosus + Phorbanta variablis, the likelihood is 0.24 (present), 0.74 (reduced), and 0.02 (absent). The likelihood reconstruction of the ancestral state of maternal care and PO was also estimated using the trimmed tree (a total of 34 terminal taxa without missing data) (Fig. 4). The proportional likelihoods for the node for maternal care and its corresponding node for the presence of PO within the Acanthosomatinae are as follows: (1) node for the presence of maternal care for Sastragala is 0.66 and its absence is 0.34 ; the node for absence of $\mathrm{PO}$ is 0.79 , for its presence, 0.21 ; (2) for $A$. denticaudum and $A$. firmatum, the node for the presence of maternal care is 0.07 , and its absence is 0.93 ; the node for the presence of PO is 0.98, and for reduction, 0.02; (3) for Elasmucha, the node for the presence of maternal care is 0.85 , and for its absence, 0.15; the node for the absence of PO is 0.92 and for its presence, 0.08 .

\section{Discussion}

\section{Multiple origins of maternal care in the acanthosomatidae}

Statistical tests rejected the possibility of a single origin for maternal egg-nymph guarding (maternal care) behavior in the Acanthosomatidae, but indicated that it has independently evolved at least three times in the subfamily Acanthosomatinae (Elasmucha, Sastragala, and Acanthosoma firmatum) and once in Blaudusinae (Sinopla perpunctatus). The multiple and independent origins of maternal care in distantly related lineages suggest that this guarding behavior did not appear as a result of phylogenetic conservatism, but it was probably driven by complex selective factors (e.g., [70]; see below).

Because Pendergrast's organ is homologous with the disc-like organ of Lestoniidae, the sister group of Acanthosomatidae, it therefore belongs to the ground plan of the clade Lestoniidae + Acanthosomatidae. It is presumably a ground plan character for Acanthosomatidae too $[61,65]$; consequently, its loss is derived. Ancestral state reconstruction suggests that maternal care has mostly likely acquired in the presence of Pendergrast's organ (Fig. 2). Moreover, no secondary loss was detected once maternal care had arisen. As maternal care seems to be resistant to loss at least in acanthosomatid bugs, and additionally it is apparently a recent acquisition in certain acanthosomatid lineages (see discussion below), our results do not support the hypothesis of Tallamy and Schaefer [9] that parental care is a plesiomorphic relic character and is 


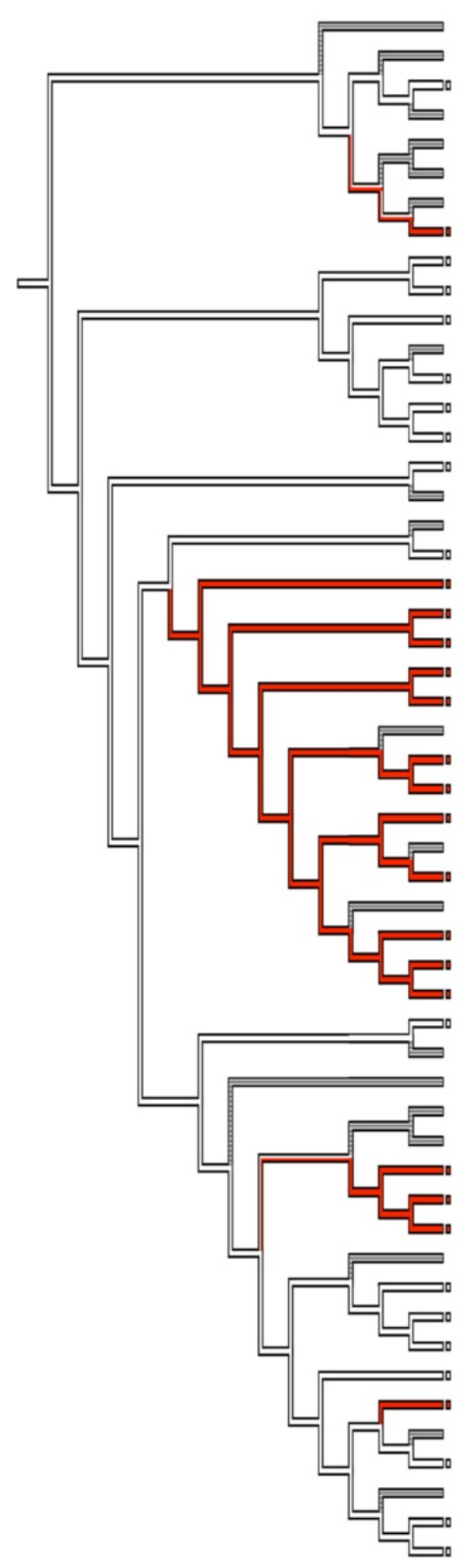

Planois gayi

Acrophyma cumingii

Ditomotarsus hyadesi

Ditomotarsus punctiventris

Lanopis rugosus

Phorbanta variabilis

Sinopla humeralis

Sinopla perpunctatus

Elasmostethus nubilus

Elasmostethus rotundus

Elasmostethus humeralis

Elasmostethus amabilis

Elasmostethus kerzhneri

Elasmostethus brevis

Elasmostethus interstinctus

Lindbergicoris gramineus

Lindbergicoris hochii

Cyphostethus japonicus

Cyphostethus tristriatus

Elasmucha nipponica

Elasmucha ferrugata

Elasmucha signoreti

Elasmucha bovilla

Elasmucha lineatum

Elasmucha laeviventris

Elasmucha dorsalis

Elasmucha putoni

Elasmucha grisea

Elasmucha broussonetiae

Elasmucha sp. (Taiwan)

Elasmucha rufescens

Elasmucha lateralis

Elasmucha amurensis

Elasmucha fieberi

Acanthosoma expansum

Lindbergicoris similis

Acanthosoma laevicorne

Acanthosoma rufescens

Acanthosoma sichuanense

Sastragala scutellata

Sastragala esakii

Sastragala sp. (javanensis complex)

Acanthosoma nigrodorsum

Acanthosoma spinicolle

Acanthosoma h. haemorrhoidale

Acanthosoma $h$. angulatum

Acanthosoma forficula

Acanthosoma firmatum $\mathbf{K}$

Acanthosoma crassicaudum

Acanthosoma denticaudum

Acanthosoma ishiharai

Acanthosoma asahinai

Acanthosoma labiduroides
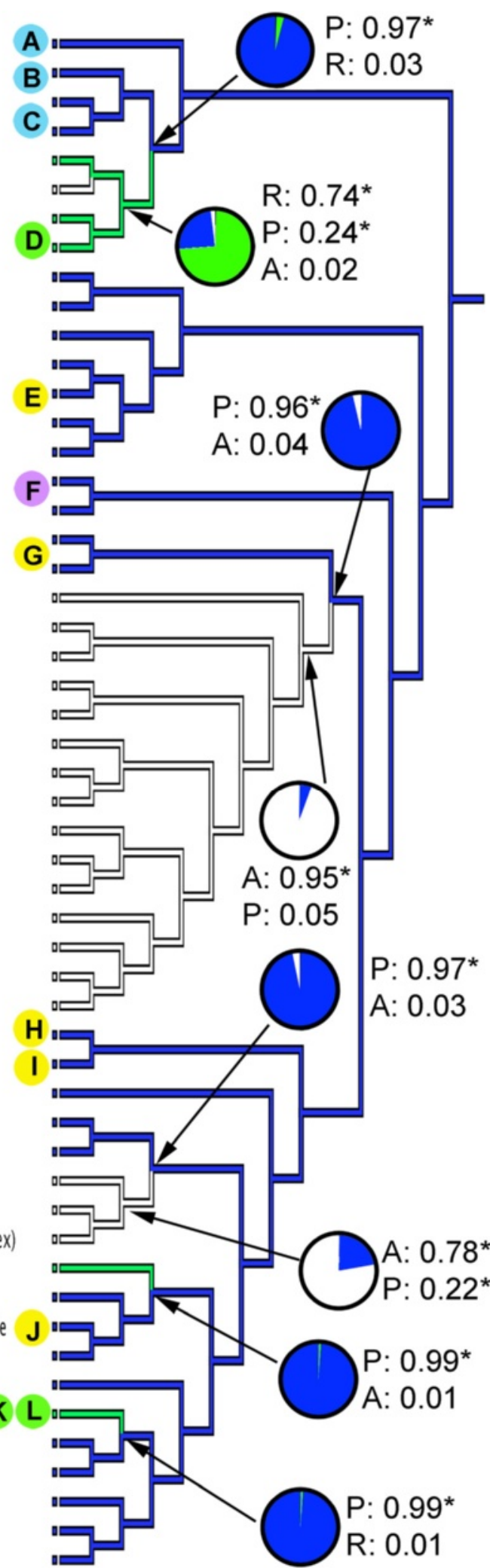

Fig. 2 (See legend on next page.) 
(See figure on previous page.)

Fig. 2 Character evolution of maternal care (left) and Pendergrast's organ (right) using parsimony based on the topology as shown in Fig. 1a. Left cladogram showing four steps under parsimony reconstruction (4 gains): red clades indicate presence of egg-nymph guarding (maternal care), white indicate absence, clades with a mixture of two colors indicate equivocal, clade in gray indicates unknown of reproductive behavior. Right cladogram showing 6 steps under parsimony reconstruction (three losses and three reductions): blue clades indicate presence of Pendergrast's organ (PO), green indicates reduced PO, white indicates absence of $\mathrm{PO}$, pie charts and values show likelihood reconstruction of nodes of interest, states judged best estimate under the threshold (2) are marked with an asterisk, letters indicate representative forms of PO shown in Fig. 3, letters with same color background have the same pattern of PO

labile, i.e., it has repeatedly appeared and been lost in Hemiptera.

\section{Correlation between maternal care and secretory organ}

As mentioned above, the secretory Pendergrast's organ (PO) is a plesiomorphic feature for the Acanthosomatidae, therefore egg smearing is an ancestral behavior (relative to egg guarding) in the family. Species showing maternal care either lack or have a reduced, non-functional PO. This organ allows the female to perform egg-smearing by coating the eggs with substances that probably have a protective function $[61,63]$. The correlation analyses convincingly indicated that the presence of maternal care is significantly correlated with the loss or reduction of the PO. Considering the strong correlation between a morphological and a behavioral trait, maternal care can be expected to occur in other genera of the family, such as Agamedes, Bebaeus, Catadipson, Ibocoris, Mahea, Phorbanta, Proctophantasta and Uhlunga, all of which invariably lack PO (also suggested by Fischer [61]). The negative correlation between the egg-nymph guarding and PO with egg-smearing behavior suggests an evolutionary trade-off between the two traits, resulting from the high physiological costs of producing and maintaining both behaviors under allocation of limited resources. Alternatively, it could be explained by a relaxed selection against redundant traits. Once alternative strategy has evolved, selective pressure for maintaining the other strategy should be relaxed. Reduction of one of the redundant traits should also be selectively advantageous for efficient allocation of resources.

Likelihood reconstruction of the ancestral state of Pendergrast's organ for the ancestral node of Acanthosoma firmatum (with reduced POs), A. denticaudum and A. crassicaudum (the latter two sibling species with welldeveloped POs) showed a significantly high proportional likelihood for the organ's presence (0.99) (Fig. 2). The trimmed tree with all available behavioral data also showed a concordant pattern between the absence of maternal care (0.93) and the presence of PO (0.98) at their ancestral node (Fig. 4). This finding indicates that the eggsmearing behavior was still present in the common ancestor of A. firmatum and A. denticaudum. Consequently, the maternal care in A. firmatum mostly likely has developed relatively recently and was followed by a subsequent reduction of the PO. The case of Acanthosoma firmatum, where females display maternal care and PO has been reduced to various degrees, might support a predicted phenotypic trade-off between different degrees of maternal care and reduction of Pendergrast's organ among and/ or within populations.

A similar scenario presumably occurred in the common ancestor of Lanopis (with two pairs of reduced POs), Phorbanta (without a PO) and Sinopla (with either a reduced or a lost $\mathrm{PO}$ ). The ancestral state reconstruction showed a significantly high proportional likelihood of reduced PO (Fig. 2, 0.74). The prediction suggests that the acquisition of maternal care precedes reduction and the loss of PO.

\section{How did the maternal care evolve in acanthosomatids?}

The evolution of paternal care in hemipteran lineages has been driven by a complex of factors. It probably originated as a response to pressure from predators and parasitoids $[43,71-76]$, to prevent eggs from desiccation [77, 78], to develop a more elaborate manipulation of tradeoffs between air exchange and desiccation in water bugs [79-82], or to represent an adaptation to unstable or ephemeral food resources in cydnid families [25, 27, 32, 83, 84]. In treehoppers, maternal care is associated with changes from a solitary to gregarious life history in connection with the acquisition of ant mutualism [2, 74].

In several species of Elasmucha (Acanthosomatinae), field experiments have demonstrated that eggs and hatched nymphs are subject to intense predation; females effectively guard them against arthropod predators [39, 41, 54-57, 85] but not against parasitoids of the nymphs [58]. These suggest that the high predation pressure is a primary factor for the acquisition of maternal care in these insects.

In addition to the selection pressure derived from the change in environmental conditions, an ancestral reproductive mode, i.e., deserting eggs after smearing, may also be associated with the emergence of maternal care. Both egg smearing and guarding behaviors share an intimate contact between the female and her eggs at the oviposition site. The smearing process itself forces the female to invest extra energy and time on each egg until forming an egg-clutch (JFT, unpublished observation). Such a prolonged stay at the oviposition site could be an exapted condition that promotes the development of maternal care. 


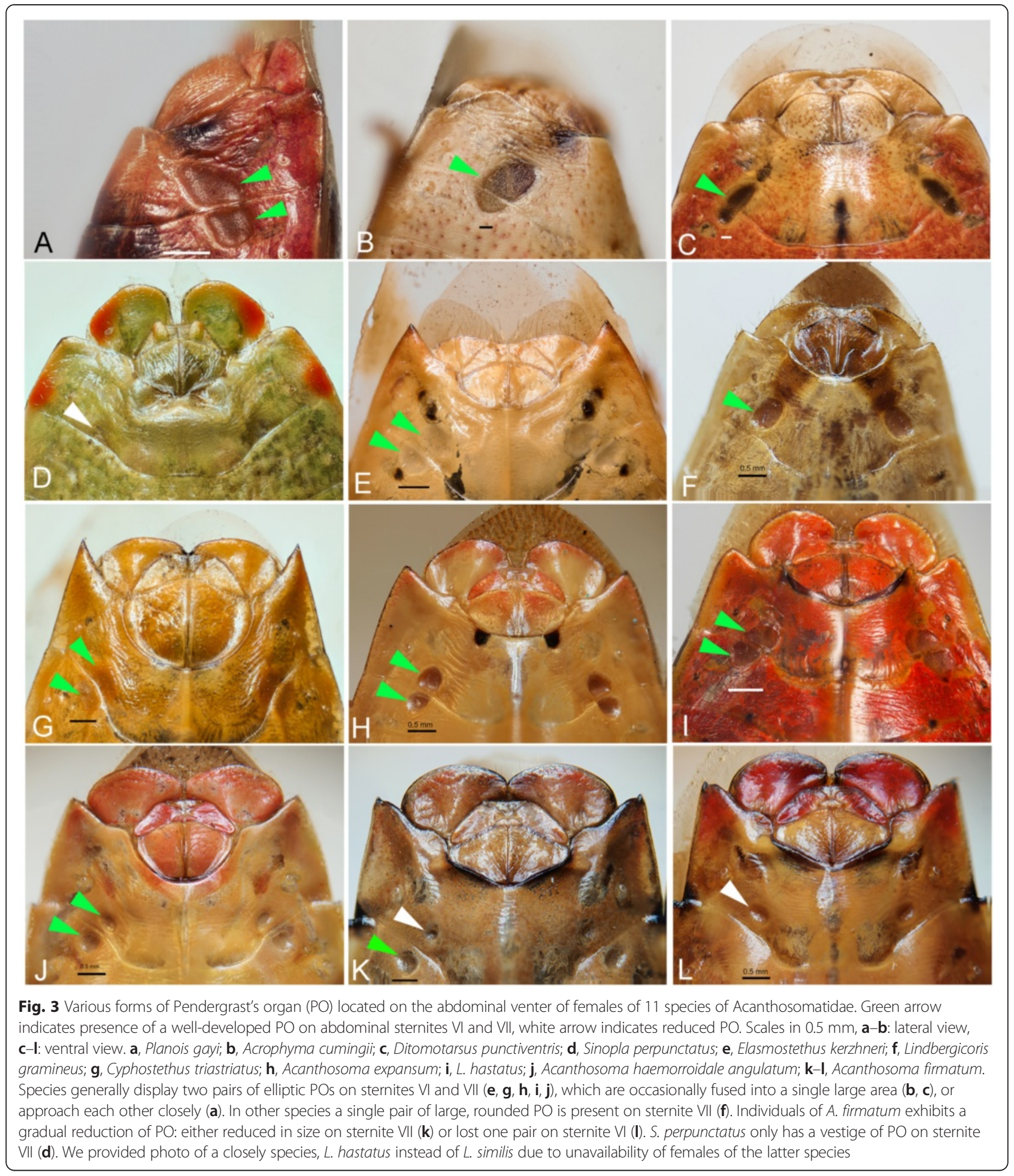

\section{Why is maternal care not lost once it has evolved in acanthosomatines?}

As our results show, maternal care has arisen from a condition with the presence of Pendergrast's organ (Fig. 2) and a strong negative correlation was found between the two traits. We presumed that both egg-smearing and egg-guarding have their own selective advantages in acanthosomatid bugs, however, once maternal care has been acquired, the Pendergrast's organ and therefore the egg-smearing will be reduced or lost because of a trade-off relationship resulting of high physiological costs of both traits. The loss of egg-nymph guarding 


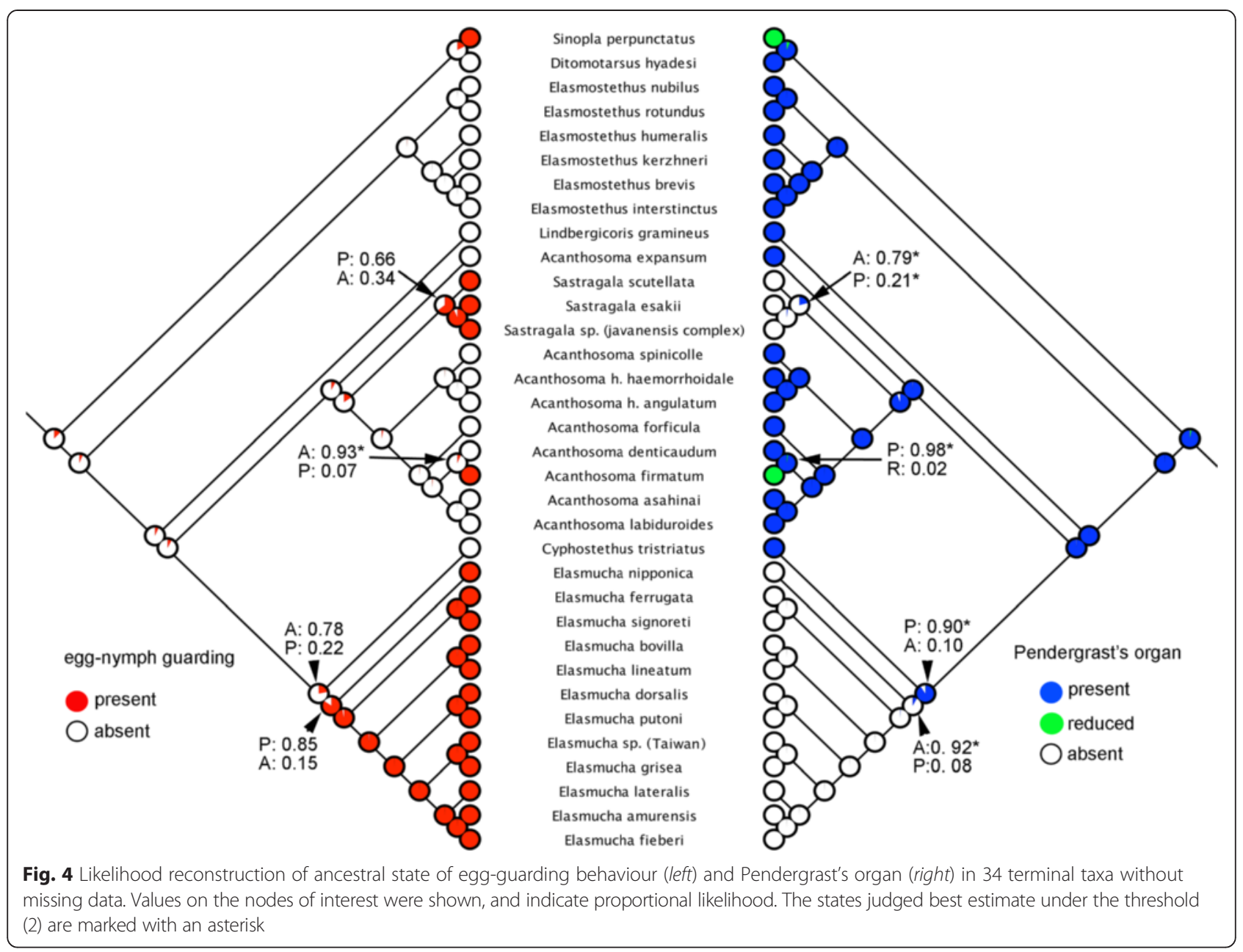

in Acanthosomatinae may also likely be inhibited due to a resulting loss of $\mathrm{PO}$, a presumably vulnerable condition which lacks any protective substances as well as female attendance. This could be why no secondary loss of the guarding behavior is observed. Even when selection favors the reduction and loss of maternal guarding as a result of a decrease in predation pressure, re-evolution of the morphologically complex PO may not be possible. Consequently, even if resources were constantly available, a potential non-caring reproductive strategy (i.e., depositing many egg batches without any protection) could not offset offspring mortalities and thus could not enjoy greater reproductive success than that from a caring strategy even under conditions of moderate predation.

In contrast, the apomorphic trait of maternal care has been lost at least once in the treehopper subfamily Membracinae due to its drastic life history specialization with the acquisition of ant mutualism [2]. Ant mutualism is apparently an alternative life history, which increases the survival of offspring more effectively than maternal guarding and consequently resulted in the secondary loss of the latter. However, such a strategy has not been observed in acanthosomatid bugs.

\section{Conclusions}

The family Acanthosomatidae is one of the best known members of Pentatomoidea, in which females of several taxa display egg-nymph guarding behavior. However, the origin and evolution of maternal care remain unclear due to the lack of a phylogenetic hypothesis. In this study, we proposed a molecular phylogeny of Acanthosomatinae for the first time. Maternal care has independently evolved at least four times within the lineages of this family. Statistical analyses rejected the possibility of a single origin within Acanthosomatinae and revealed at least three independent origins among the distantly related lineages. Our results revealed that maternal care is an apomorphy (relative to egg smearing), which has arisen in the presence of secretory Pendergrast's organ, where their common ancestor still exhibits a plesiomorphic reproductive trait, i.e., deserting the eggs after smearing. A negative evolutionary correlation suggests a trade-off between the acquisition of 
maternal care and the reduction or loss of the secretory organ. Alternatively, this negative correlation is possibly a consequence of relaxed selection against one of two redundant traits. The presence of maternal care is to be highly expected in other genera that also lack or have a reduced, unfunctional organ. Previous studies indicate that the evolution of maternal guarding is driven by high predation pressure. Although maternal guarding might be easily lost in a low-risk environment, it seems resistant to such lost in acanthosomatids. We found that no secondary loss of maternal care occur once it has evolved. The maintenance of maternal care in acanthosomatids are likely due to a vulnerable Pendergrast's-organ-free condition. Our phylogenetic hypothesis provides a basis for future comparative analyses of the evolution of parental care and other reproductive traits. The multiple origins of maternal care estimated here will enable us to further test general hypotheses about the ecological and life-history conditions favoring care as well as about the evolutionary trends with other reproductive traits, such as egg size.

\section{Methods}

\section{Taxon sampling}

A total of 53 terminal taxa were included in the study (Additional file 3). The ingroup consisted of 44 species and one subspecies belonging to six genera of Acanthosomatinae and covered all representative members for which published data are available on maternal care. An additional eight species in six genera belonging to the other two subfamilies were included as outgroups and were used to root the phylogenetic tree.

\section{Molecular markers and primers}

Five genes including mitochondrial protein-coding (Cytochrome Oxidase I [COI]), two ribosomal genes (12S and 16S), nuclear protein-coding (Histone 3 [H3]) and ribosomal genes $(18 S)$ were sequenced. Primer sets for the target regions, COI (LCO1490-HCO2198, [86]), $12 \mathrm{~S}$ (12Sai-12Sbi, [92]), $16 \mathrm{~S}$ (16Sar-16Sbr, [87]), H3 (HexAFHexAR, [88]), and 18S (NS1-NS2a, [89]) were used for amplification and sequencing.

\section{DNA extraction and purification, PCR amplification, and sequencing}

All specimens were preserved in $99.5 \%$ ethanol in the field, followed by long-term storage at $-20{ }^{\circ} \mathrm{C}$. The thoracic muscles and legs were digested in Proteinase $\mathrm{K}$ solution for $12-18 \mathrm{~h}$ at $56{ }^{\circ} \mathrm{C}$ in an incubator and then used for DNA extraction following the standard protocols suggested by the Qiagen DNeasy Tissue kit (Qiagen). PCR reaction cycles were performed with an initial denaturing step at $94{ }^{\circ} \mathrm{C}$ for $3 \mathrm{~min}$, followed by 35 cycles of $94{ }^{\circ} \mathrm{C}$ for $30 \mathrm{~s}$, $42{ }^{\circ} \mathrm{C}(16 S), 45^{\circ} \mathrm{C}(12 S), 50{ }^{\circ} \mathrm{C}(\mathrm{COI}, 18 S)$ or $54{ }^{\circ} \mathrm{C}(\mathrm{H} 3)$ for $30 \mathrm{~s}$ and $72{ }^{\circ} \mathrm{C}$ for $1 \mathrm{~min}$. DNA samples were sequenced by
CEQ 2000XL DNA Analysis System (Beckman Coulter, California, USA) following the manufacturer's protocols.

\section{Sequence alignment and phylogenetic analyses}

Alignments of Histone 3 and $\mathrm{COI}$ were straightforward and based on amino acid sequences. Mitochondrial rDNA was aligned using ClustalX 2.1 [90] with Gap:Gap-extension costs $=10: 1$ and 20:0.1 to recover the maximum numbers of stem regions [91]. The same software and cost-set was also applied to the alignment of $18 \mathrm{~S}$ rDNA. The alignment was adjusted manually by eye, and ambiguously aligned regions were excluded from the analyses based on similarity criterion [92], resulting in a concatenated alignment of $2182 \mathrm{bp}$. Aligned data in nexus format are available as Additional file 4.

We performed maximum likelihood (ML) and Bayesian analyses. For ML analyses, a heuristic search with Tree Bisection and Recombination (TBR) branch swapping using a Neighbor Joining starting tree was performed by PAUP* 4.0b10 [93]. The best-fit substitution model was estimated using hierarchical likelihood ratio tests (hLRT) as implemented in jModeltest 2.1.5 [94, 95], and the GTR + I + G model was selected (unequal base frequencies: $A=0.2974, C=0.1616, G=0.1863, T=0.3547$; six substitution categories: $A-C=3.0456, A-G=13.8985$, $\mathrm{A}-\mathrm{T}=5.8488, \quad \mathrm{C}-\mathrm{G}=1.2926, \mathrm{C}-\mathrm{T}=28.9260, \quad \mathrm{G}-\mathrm{T}=1$; gamma distributions shape parameter $=0.5330$ based on four rate categories; proportion of invariant sites $=0.6260$ ). ML-based bootstrap values were calculated using PhyML 3.0 [96] with the GTR model and estimated parameters with 1000 replications.

For Bayesian analysis, we separated the characters into nine partitions $(12 S, 16 S, 18 S$, three codon positions of $\mathrm{H} 3$ and $\mathrm{COI}$, respectively). The best-fit model was estimated independently for each partition using hLRTs as implemented in MrModeltest 2.2 [97], resulting in $12 S$, $16 S$, the first codon of $C O I(G T R+I+R)$, the second codon of COI $(\mathrm{F} 81+\mathrm{G})$, third codon of $\mathrm{COI}(\mathrm{GTR}+\mathrm{G})$, $18 S(\mathrm{~K} 80+\mathrm{G})$, the first coden of $H 3(\mathrm{~F} 81)$, second conden of $H 3$ (JC), third conden of $H 3(\mathrm{SYM}+\mathrm{G})$. Bayesian analysis was conducted using MrBayes 3.1.2 [98] with two runs of four chains each for 2,000,000 generations and tree samples every 1000 generations. The first $50 \%$ of the trees were discarded as a burn-in, and a $50 \%$ majority consensus tree was used to calculate posterior probabilities.

\section{Constraint analyses}

The likelihood of competing hypotheses of maternal care evolution was tested statistically by using the constraint trees. To test whether the maternal care is of single origin, species with maternal care were constrained as monophyletic group while the rest species were collapsed to polytomies, and likelihood scores was compared with the best 
ML tree. All constraint ML topologies were estimated with the same substitution model and tree searching algorithm as used for the MLtree search. The non-parametric likelihood ratio test was performed by the ShimodairaHasegawa test (test distribution set as RELL) and KishinoHasegawa test (two-tailed).

\section{Data collection for Pendergrast's organ and reproductive behavior}

Surveys on the character distributions and states of Pendergrast's organ in all terminal taxa, comprising 53 species, are based on our observations from the alcoholpreserved and dry museum specimens.

To determine whether females show maternal care, we collected gravid females of each species, confined them in rearing cases with host plants, and then checked for oviposition under laboratory conditions. For some species, we observed maternal care directly under field conditions. Maternal care can be easily recognized in acanthosomatids by the remarkable posture and behavior of females; caring females invariably straddle egg masses and hatchlings tightly (Fig. 1b, c, d), and when disturbed, it shows specific aggressive responses, e.g., tilting the body towards the source of disturbance $[36,37,41,54,56]$. On the other hand, females of asocial species always leave oviposition sites soon after depositing egg mass. Data on the reproductive behavior of eight species are referred from the literatures [20,42, 61, 68, 99, 100, 105]; detailed information on the caring behavior in two additional species, $E$. lineata and Sastragala sp. was obtained from J. Horstman (pers. comm.). Including records from the literatures, we obtained data on reproductive behavior for 34 species (Additional file 3).

\section{Tracing character evolution}

Behavioral data and condition of Pendergrast's organ (PO) were listed in Additional file 3, and the corresponding of character the coding matrix refers to Additional file 5. Species lacking of behavioral data were coded as missing (19 out of 53 species). Behavior of eggnymph guarding is treated as a binary character (present or absent). The character of PO was coded as three states: absent, present, and reduced (Additional file 5). Characters were mapped on the Bayesian tree according to the parsimony criterion produced by Mesquite 3.02 [101]; matrix refers to Additional file 6. For reconstruction of the ancestral state of PO, a likelihood criterion was performed by Mesquite 3.02. The same method was also applied to the trimmed tree (the same topology for Pagel's correlation test) with likelihood reconstruction for maternal care and PO; matrix refers to Additional file 7. The current probability model of the Bayesian tree was used as the source of a character model for likelihood reconstruction at each node. The likelihood decision threshold is two as the default (the commonly used value proposed by Pagel [102]).

\section{Correlated evolution analysis}

To determine whether a correlation between the presence of maternal care and absence of Pendergrast's organ is significant, we performed two statistical methods using the concentrated-changes test [69] and likelihood-based correlation method [103]. For character coding, we modified the matrix of Additional file 5 into binary characters (Addition file 8), and treated a reduced Pendergrast's organ as "absent" state because the scanning electron microscope observations and histological evidences suggest a loss of the secretory function in the reduced organ (JFT, unpublished observation). We removed those taxa with missing data (a total of 19 species lacking behavioral information), and maintained the shape of the Bayesian topology (Fig. 1a) as the backbone tree for the analyses of correlated evolution. In the concentrated-changes test, we performed three respective options with MacClade 4.08a [104]: actual changes, MINSTATE and MAXSTATE reconstructions for numbers of gains and losses of Pendergrast's organ. We indicate the " 0 " (absent) and "equivocal" state for the choice of distinguishing branches as those having in the character traced under 0 gains and four losses over the whole cladogram for 1,000,000 simulations. To avoid an assumption of actual changes, the other two algorithms of reconstructed-changes were performed in MINSTATE and MAXSTATE and given "1" (present) as the initial state and "0" as compensation. We also performed Pagel's correlation analysis using Mesquite 3.02 [101]. The branch length of the trimmed tree (with 34 terminal taxa) was re-estimated by the Bayesian method for the correlation test. Pagel's test was set as "any effect" by designating Pendergrast's organ and maternal care as either X or Y. The likelihood difference between independent and dependent (= correlated) models was estimated for 1000 simulations. Differences in the likelihood of the independent versus correlated models of evolution were estimated where $P$-values below 0.05 indicate a significant correlation between the the two traits.

\section{Observations of egg-smearing behavior}

Egg-smearing behaviour was successfully documented in five species using a digital camera (Olympus Digital Camera TG-2): Acanthosoma denticaudum, A. haemorrhoidale angulatum, A.labiduroides, Elasmostethus humeralis, and E. interstinctus. Overwintering females were collected from their host plants at the campus of Hokkaido University (Sapporo), Forestry and Forest Products Research Institute (Hokkaido Research Center, Hitsujigaoka, Sapporo) and Zenibako-gawa (Otaru) from mid June to early July in 2013 and 2014. None of these are endangered or protected species and no permits were required 
for their study. Gravid females were reared individually in transparent Petri dishes $(9 \mathrm{~cm}$ diameter, $3.5 \mathrm{~cm}$ height) supplied with shoots of Japanese rowan (Sorbus commixta), hornbeam (Carpinus cordata) or hogweed (Heracleum dulce) bearing fresh fruits. For determining the active oviposition period, the animals were observed every $30 \mathrm{~min}$ from 10:00 to 22:00. If a female was found in ovipositing posture (i.e., bending the antennae backward and against the body, standing with the hind tarsi close together under the tip of the abdomen, and exhibiting slight movements of the valvifers accompanied by stamping of the hind legs for measuring the egg-laying site), then we started recording using movie mode of an Olympus digital camera in super macro mode. Two common species, Elasmostethus humeralis and Acanthosoma denticaudum, were selected as models for demonstrating the eggsmearing behavior (see Additional files 1 and 2).

\section{Availability of supporting data}

The data sets supporting the results of this article are available in Additional files.

\section{Additional files}

Additional file 1: Format: MPEG 4. Title: Egg-smearing behavior of Elasmostethus humeralis. Legend: Female of Elasmostethus humeralis ovipositing on a fruit of the hogweed (Heracleum dulce); natural speed. After the egg is laid the female spends about $1 \mathrm{~min}$ to spread the secretion onto each of the eggs, one after another, with its hind legs rubbing against Pendergrast's organ (PO). First part (dorsal view): note that the diagonal movements of the left and right legs follow each other almost without interruption. Second part (close-up in lateral view): rubbing each of hind tarsi and tips of tibiae alternatively and repeatedly against PO. Third part (posterior view): initial process of egg-laying; after the egg is deposited the female immediately starts smearing it. (M4V $17537 \mathrm{~kb}$ )

Additional file 2: Format: MPEG 4. Title: Egg-smearing behavior of Acanthosoma denticaudum. Legend: Female of Acanthosoma denticaudum ovipositing on a leaf of Japanese rowan (Sorbus commixta). Note the short interruption (about $1 \mathrm{~s}$ ) between the movements of both legs during smearing. (M4V $13586 \mathrm{~kb}$ )

Additional file 3: Format: XLS. Title: Species sequenced in the study, behavioral data, and condition of Pendergrast's organ on the pregenital segments. Legend: Symbols: + (present), - (absent), R (reduced). 'This species is conspecific with Acanthosoma giganteum Matsumura, recently synonymized by Tsai \& Rédei [53]; the junior synonymous name, $A$. giganteum, is frequently cited, and its mitochondrial gene of cytochrome oxidae subunit I ( $m$ tDNA-COI) is also available from GenBank (AB368853). ${ }^{2}$ An undescribed species closely related to S. javanensis Distant. Collection abbreviation: JFT- Jing-Fu Tsai's coll. deposited in systematic laboratory of Hokkaido University, Sapporo, Japan; NKU- Department of Zoology and Developmental Biology, Nankai University, Tianjin, China. LC099108LC099371: Genbank accession numbers. (XLS 56 kb)

Additional file 4: Format: nexus. Title: Data matrix of aligned sequences for Bayesian analysis. (NEX $130 \mathrm{~kb}$ )

Additional file 5: Format: XLS. Title: Data matrix for character evolution. Legend: Data matrix for character evolution. Character 1, egg-nymph guarding behaviour (maternal care) $[0=$ absent, $1=$ present, ? = missing data]. Character 2, Pendergrast's organ $[0=$ absent, $1=$ present $2=$ reduced]. (XLSX $10 \mathrm{~kb})$
Additional file 6: Format: nexus. Title: Data matrix for parsimonious reconstruction of the two traits (maternal care and Pendegrast's organ) on 53 species, including species with missing data. (NEX $20 \mathrm{~kb}$ )

Additional file 7: Format: nexus. Title: Data matrix for likelihood reconstruction of ancestral state of the two traits (maternal care and Pendegrast's organ) on 34 species with confirmed behavior data. (NEX $16 \mathrm{~kb}$ )

Additional file 8: Format: XLS. Title: Data matrix for correlation analysis. Legend: Data matrix for correlation analysis between maternal care and Pendergrast's organ. Character 1, egg-nymph guarding behaviour (maternal care) $[0=$ absent, $1=$ present $]$. Character two, Pendergrast's organ $[0=$ absent or reduced, see explanation in Methods, $1=$ present $]$. (XLS $31 \mathrm{~kb})$

\section{Competing interests}

The authors declare that they have no competing interests.

\section{Authors' contributions}

JFT and SK conceived the study; JFT and SK carried out field work and behavioural observation; JFT generated the molecular data and conducted all DNA sequence; JFT and KY performed phylogenetic and statistical analyses; JFT, SK and KY wrote the paper. All authors read and approved the final manuscript.

\section{Acknowledgements}

We are very grateful to Eduardo I. Faúndez, Máriom A. Carvajal, Petr Kment, Petr Baňař, Jitka Vilímova, Qiang Xie, Sheng-Chung Zheng, M. Javahery, Atsushi Honma, Takuma Yoshida, Takahiro Hosokawa, Yoshitomo Kikuchi, Aki Yamamoto, Shinji Yano, Wataru Ogasa, Tadao Ichita, Eiichi Hara, Tadashi Ishikawa, Yoshitaka Kamimura, Satoshi Maehara, Yoko Matsumura, Seizo Okuno, Takuya Takemoto, Hirotaka Tanaka for providing valuable specimens; to Izumi Yao for assistance and consultation of some technical details of molecular work; to Johanna Mappes for information on bugs and support during field work in Finland; to Yi-Xuan Hsieh and John Horstman for their courtesy of sharing photos and field observations. We also thank Hokkaido Research Center, Forestry and Forest Products Research Institute for permission to collect insects. We are indebted to Dávid Rédei for useful comments on the manuscript. Two anonymous reviewers provided constructive criticisms. This study received financial support from the Japanese Society for Promotion of Science to JFT and KY (project no. 13 F03075), and to KY (project no. 15H04409).

\section{Author details}

'Systematic Entomology, School of Agriculture, Hokkaido University, Sapporo 060-8589, Japan. ${ }^{2}$ Department of Biology, Naruto University of Education, Naruto, Tokushima 772-8502, Japan. ${ }^{3}$ Department of Biology, National Museum of Natural Science, Taichung 40427, Taiwan.

Received: 5 August 2015 Accepted: 10 November 2015 Published online: 19 November 2015

\section{References}

1. Costa JT. The other insect societies. Cambridge: Harvard University Press; 2006.

2. Lin CP, Danforth BN, Wood TK. Molecular phylogenetics and evolution of maternal care in membracine treehoppers. Syst Biol. 2004;53:400-21.

3. Gilbert JDJ, Manica A. The evolution of parental care in insects: a test of current hypotheses. Evolution. 2015;69:1255-70.

4. Reynolds JD, Goodwin NB, Freckleton RP. Evolutionary transitions in parental care and live bearing in vertebrates. Philos Transac R Soc Lond B Biol Sci. 2002;357:269-81.

5. Balshine S. Patterns of parental care in vertebrates. In: Royle NJ, Smiseth PT, Kölliker M, editors. Evolution of parental care. Oxford: Oxford University Press; 2012. p. 62-80.

6. Trumbo ST. Patterns of parental care in vertebrates. In: Royle NJ, Smiseth PT, Kölliker M, editors. Evolution of parental care. Oxford: Oxford University Press; 2012. p. 81-100.

7. Mank JE, Promislow DE, Avise JC. Phylogenetic perspectives in the evolution of parental care in ray-finned fishes. Evolution. 2005;59:1570-78.

8. Gardner A, Smiseth PT. Evolution of parental care driven by mutual reinforcement of parental food provisioning and sibling competition. Proc Royal Soc B. 2011; doi:10.1098/rspb.2010.1171 
9. Tallamy DW, Schaefer CW. Maternal care in the Hemiptera: ancestry, alternatives and current adaptive value. In: Choe JC, Crespi BJ, editors. The evolution of social behavior in insects and arachnids. Cambridge: Cambridge University Press; 1997. p. 94-115.

10. Tachikawa S. Studies on the subsociality of Japanese Heteroptera. Tokyo: Tokyo University of Agriculture Press; 1991.

11. Gogala M, Yong H, Brühl C. Maternal care in Pygoplatys bugs (Heteroptera: Tessaratomidae). Eur J Entomol. 1998;95:311-15.

12. Tallamy DW, Igaly R. Maternal care in Compseuta picta, an African lace bug (Heteroptera: Tingidae). J Insect Behav. 2004;17:247-49.

13. Monteith GB. Maternal care in Australian oncomerine shield bugs (Insecta, Heteroptera, Tessaratomidae). In: Rabitsch W, editor. Hug the bug - For love of true bugs. Festschrift zum 70. Geburtstag von Ernst Heiss. Denisia. 19th ed. 2006. p. 1135-52.

14. Goula M. Parental care in Heteroptera (Hemiptera: Prosorhynche). In: Capinera JL, editor. Encyclopedia of entomology, 3. 2nd ed. Dordrecht: Springer Science; 2008. p. 2743-55.

15. Requena GS, Nazareth TM, Schwertner CF, Machado G. First cases of exclusive paternal care in stink bugs (Hemiptera: Pentatomidae). Zool. 2010;27:1018-21.

16. Forero $\mathrm{D}$, Choe $\mathrm{DH}$, Weirauch $\mathrm{C}$. Resin gathering in neotropical resin bugs (Insecta: Hemiptera: Reduviidae): functional and comparative morphology. J Morphol. 2011;272:204-29.

17. Tallamy DW. Sexual selection and the evolution of exclusive parental care in arthropods. Anim Behav. 2000;60:559-67.

18. Tallamy DW. Evolution of exclusive paternal care in arthropods. Ann Rev Entomol. 2001;46:139-65.

19. Tachikawa S. Studies on parental care of Heteroptera I. On Elasmucha putoni of Japan and other Elasmucha spp. J Agric Sci Tokyo Nogyo Daigaku. 1971;18:24-34

20. Hanelová J, Vilímová J. Behaviour of the central European Acanthosomatidae (Hemiptera: Heteroptera: Pentatomoidea) during oviposition and parental care. Acta Mus Moraviae, Sci Boil. 2013;98:433-57.

21. Guilbert E. Habitat use and maternal care of Phloea subquadrata (Hemiptera: Phloeidae) in the Brasilian Atlantic forest (Espirito Santo). Eur J Entomol. 2003;100:61-3.

22. Mappes J, Kaitala A, Alatalo RV. Joint brood guarding in parent bugs - an experiment on defence against predation. Behav Ecol Sociobiol. 1995;36:343-47.

23. Roth S, Adaschkiewitz W, Fischer C. Notes on the bionomics of Elasmucha grisea (Linnaeus, 1758) (Heteroptera, Acanthosomatidae) with special regard to joint guarding. In: Rabitsch W, editor. Hug the bug - For love of true bugs. Festschrift zum 70. Geburtstag von Ernst Heiss. Denisia. 19th ed. 2006. p. 1153-67.

24. Site RW, McPherson JE. Life history and laboratory rearing of Sehirus cinctus cinctus (Hemiptera: Cydnidae), with descriptions of immature stages. Ann Entomol Soc Am. 1982;75:210-15.

25. Tsukamoto $L$, Tojo $S$. A report of progressive provisioning in a stink bug, Parastrachia japonensis (Hemiptera: Cydnidae). J Ethol. 1992;10:21-9.

26. Nakahira T. Production of trophic eggs in the subsocial burrower bug Admerus (sic) triguttulus. Naturwissenschaften. 1994;81:413-14.

27. Filippi L, Hironaka M, Nomakuchi S, Tojo S. Provisioned Parastrachia japonensis (Hemiptera: Cydnidae) nymphs gain access to food and protection from predators. Anim Behav. 2000;60:757-63.

28. Filippi L, Baba N, Inadomi K, Yanagi T, Hironaka M, Nomakuchi S. Pre-and post-hatch trophic egg production in the subsocial burrower bug, Canthophorus niveimarginatus (Heteroptera: Cydnidae). Naturwissenschaften. 2009:96:201-11.

29. Kudo S, Nakahira T. Effects of trophic-eggs on offspring performance and rivalry in a sub-social bug. Oikos. 2004;107:28-35.

30. Hironaka M, Nomakuchi S, Iwakuma S, Filippi L. Trophic egg production in a subsocial shield bug, Parastrachia japonensis Scott (Heteroptera: Parastrachiidae), and its functional value. Ethology. 2005;11:1089-102.

31. Nakahira T, Kudo S. Maternal care in the burrower bug Adomerus triguttulus: defensive behavior. J Insect Behav. 2008;21:306-16.

32. Nakahira T, Tanaka KD, Kudo S. Maternal provisioning and possible joint breeding in the burrower bug Adomerus triguttulus (Heteroptera: Cydnidae). Entomol Sci. 2013;16:151-61.

33. Mukai H, Hironaka M, Baba N, Yanagi T, Inadomi K, Filippi L, et al. Maternalcare behaviour in Adomerus variegatus (Hemiptera: Cydnidae). Can Entomol. 2010;142:52-6.
34. Mukai H, Hironaka M, Tojo S, Nomakuchi S. Maternal vibration: an important cue for embryo hatching in a subsocial shield bug. Plos One. 2014. doi:10.1371/journal.pone.0087932

35. Inadomi K, Wakiyama M, Hironaka M, Mukai H, Filippi L, Nomakuchi S. Postovipositional maternal care in the burrower bug, Adomerus rotundus (Hemiptera: Cydnidae). Can Entomol. 2014;146:211-18.

36. Hasegawa $\mathrm{H}$. Life history of the subsocial bug: egg-guarding behavior of Sastragala esakii. In: Iwata K, Hurukawa H, Yasumatsu K, editors. Subsocial Insects. Nihon Kontyû-ki IV. Tokyo: Kôdansha; 1967. p. 145-78.

37. Kudo S. Brooding behavior in Elasmucha putoni (Heteroptera: Acanthosomatidae), and a possible nymphal alarm substance triggering guarding responses. Appl Entomol Zool. 1990;25:431-37.

38. Kudo S. Intraclutch egg-size variation in acanthosomatid bug: adaptive allocation of maternal investment? Oikos. 2001:92:208-14.

39. Kudo S. Phenotypic selection and function of reproductive behavior in the subsocial bug Elasmucha putoni (Heteroptera: Acanthosomatidae). Behav Ecol. 2002;13:742-49.

40. Kudo S. Within-clutch egg-size variation in a subsocial bug: the positional effect hypothesis. Can J Zool. 2006;84:1540-44

41. Kudo S, Nakahira T. Brooding behavior in the bug Elasmucha signoreti (Heteroptera: Acanthosomatidae). Psyche. 1993;100:121-26.

42. Kaitala A, Mappes J. Parental care and reproductive investment in shield bugs (Acanthosomatidae, Heteroptera). Oikos. 1997;80:3-7.

43. Mappes J, Mappes T, Lappalainen T. Unequal maternal investment in offspring quality in relation to predation risk. Evol Ecol. 1997;11:237-43.

44. Yamamoto A, Hayashi M, Kudo S. Host plants of Japanese acanthosomatid bugs (Heteroptera: Acanthosomatidae). Jpn J Entomol. 2009;12:31-8.

45. Kumar R. A revision of world acanthosomatidae (Heteroptera: Pentatomoidea): keys to and descriptions of subfamilies, tribes and genera, with designation of types. Aust J Zool Suppl Ser. 1974;34:1-60.

46. Rolston LH, Kumar R. Two new genera and two new species of Acanthosomatidae (Hemiptera) from South America, with a key to the genera of the Western Hemisphere. J N Y Entomol Soc. 1975;82:271-78.

47. Ahmad I, Moizuddin M. Aspects of internal anatomy of Ameenocoris pakistanensis Ahmad and Moizuddin (Pentatomoidea Acanthosomatidae) from Pakistan with reference to phylogeny. Karachi Univ J Sci. 1990;18:165-71.

48. Kment P. Revision of Mahea Distant, 1909, with a review of the Acanthosomatidae (Insecta: Heteroptera) of Madagascar and Seychelles. Acta Entomol Mus Nat Pragae. 2005:45:21-50.

49. Faúndez El. A new genus for a Chilean species of Acanthosomatidae (Hemiptera: Heteroptera). Zootaxa. 2014;3768:596-600.

50. Faúndez El, Rider DA, Carvajal MA. Cochabambia Pirán, 1959 (Hemiptera: Heteroptera: Acanthosomatidae), a senior homonym of Cochabambia Marcuzzi, 1985 (Coleoptera: Tenebrionidae), with notes on the placement of Cochabambia Pirán. Zootaxa. 2014;3793:595-96.

51. Faúndez El, Carvajal MA, Rider DA. Archaeoditomotarsus crassitylus, gen and sp. nov. (Hemiptera: Heteroptera: Acanthosomatidae) from Chile. Zootaxa. 2014;3860:87-91.

52. Tsai JF, Rédei D. The identity of Acanthosoma vicinum, with proposal of a new genus and species level synonymy (Hemiptera: Heteroptera: Acanthosomatidae). Zootaxa. 2015;3936:375-86.

53. Tsai JF, Rédei D. Redefinition of Acanthosoma and taxonomic corrections to its included species (Hemiptera: Heteroptera: Acanthosomatidae). Zootaxa. 2015:3950:1-60.

54. Melber A, Schmidt GH. Sozialverhalten zweier Elasmucha-Arten. Zeitschr Tierpsychol. 1975:39:403-14.

55. Melber A, Hölscher L, Schmidt GH. Further studies on the social behaviour and its ecological significance in Elasmucha grisea L. (Hem.-Het.: Acanthosomatidae). Zool Anz. 1980;205:27-38.

56. Kudo S, Sato M, Ohara M. Prolonged maternal care in Elasmucha dorsalis (Heteroptera: Acanthosomatidae). J Ethol. 1989;7:75-81.

57. Mappes J, Kaitala A. Experiments with Elasmucha grisea L. (Heteroptera: Acanthosomatidae): does a female parent bug lay as many eggs as she can defend? Behav Ecol. 1994;5:314-17.

58. Kudo S. Inefective maternal care of a subsocial bug against a nymphal parasitoid: a possible consequence of specialization to predeators. Ethology. 1996;102:227-35.

59. Pendergrast JG. Studies on the biology of pentatomid bugs in the genus Rhopalimorpha Dallas (Heteroptera). Trans Roy Soc New Zealand. 1952;80:143-53. 
60. Carter ME, Hoebeke ER. Biology and seasonal history of Elasmostethus atricornis (Van Duzee) (Hemiptera: Acanthosomatidae), with descriptions of the immature stages and notes on Pendergrast organ. Proc Entomol Soc Wash. 2003;105:525-34.

61. Fischer $\mathrm{C}$. The biological context and evolution of Pendergast's organs of Acanthosomatidae (Heteroptera, Pentatomoidea). In: Rabitsch W, editor. Hug the bug - For love of true bugs. Festschrift zum 70. Geburtstag von Ernst Heiss. Denisia. 19th ed. 2006. p. 1041-54.

62. Pendergrast JG. Setose areas on the abdomen in female of some Acanthosominae (Heteroptera, Pentatomidae). Entomologist. 1953;86:135-38.

63. Aldrich JR. Chemical ecology of the Heteroptera. Ann Rev Entomol. 1988;33:211-38.

64. Fischer C. Das Pendergrast-Organ der Acanthosomatidae (Heteroptera, Pentatomoidea): Schutz des Eigeleges vor Raubern und Parasiten? Sitzungsb Ges Naturforsch Freunde Berlin (NF). 1994;33:129-42.

65. Fischer $\mathrm{C}$. The disc-like organ of the Lestoniidae (Heteroptera: Pentatomoidea), with remarks on lestoniid relationships. Insect Syst Evol. 2000;31:201-8.

66. Grazia J, Schuh RT, Wheeler WC. Phylogenetic relationships of family groups in Pentatomoidea based on morphology and DNA sequences (Insecta: Heteroptera). Cladistics. 2008;24:932-76.

67. Hayashi M. Parental care observed in Anaxandra gigantea (Heteroptera, Acanthosomatidae). Rostria. 1987;38:569-70.

68. Faúndez El, Osorio GA. New data on the biology of Sinopla perpunctatus Signoret, 1864 (Hemiptera: Heteroptera: Acanthosomatidae). Bol Biodivers Chile. 2010;3:24-31.

69. Maddison WP. A method for testing the correlated evolution of two binary characters: are gains or losses concentrated on certain branches of a phylogenetic tree? Evolution. 1990;44:539-57.

70. Wong JWY, Meunier J, Kölliker M. The evolution of parental care in insects: the roles of ecology, life-history and the social environment. Ecol Entomol. 2013;38:123-37.

71. Eberhard WG. The ecology and behavior of a subsocial pentatomid bug and two scelionid wasps: strategy and counterstrategy in a host and its parasitoids. Smithson Contrib Zool. 1975;205:1-39.

72. Tallamy DW, Denno RF. Maternal care in Gargaphia solani (Hemiptera; Tingidae). Anim Behav. 1981;29:771-78.

73. Nakamura K. Maternal care and survival in a sumatran Physomerus grossipes. In: Sakagami SF, Phgushi R, Roubik DW, editors. Natural history of social wasps and bees in equatorial Sumatra. Sapporo: Hokkaido University Press; 1990. p. 233-43.

74. Lin CP. Social behaviour and life history of membracine treehoppers. J Nat Hist. 2006;40:1887-907.

75. Gilbert JDJ, Thomas LK, Manica A. Quantifying the benefits and costs of parental care in assassin bugs. Ecol Entomol. 2010;35:639-51.

76. Giffney RA, Kemp DJ. Does it pay to care?: Exploring the costs and benefits of parental care in the Hibiscus Harlequin Bug Tectocoris diophthalmus (Heteroptera: Scutelleridae). Ethology. 2014;120:607-15.

77. Ichikawa N. Male brooding behavior of the giant water bug Lethocerus deyrollei. J Ethol. 1988;6:121-27.

78. Smith RL. Evolution of paternal care in the giant water bugs (Heteroptera: Belostomatidae). In: Choe JC, Crespi BJ, editors. The evolution of social behavior in insects and arachnids. Cambridge: Cambridge University Press; 1997. p. 116-49.

79. Cullen MJ. The biology of the giant water bugs (Hemiptera: Belostomatidae) in Trinidad. Proc R Entomol Soc London. 1969;44:123-37.

80. Smith RL. Male brooding behavior of the water bug Abedus herberti (Hemiptera: Belostomatidae). Ann Entomol Soc Am. 1976;69:740-47.

81. Smith RL. Brooding behavior of a male water bug Belostoma flumineum (Hempitera: Belostomatidae). J Kans Entomol Soc. 1976;49:333-43.

82. Jawale SM, Ranade DR. Observations on the parental care in Sphaerodema (= Diplonychus) rusticum Fabr. Geobios. 1988;15:44-6.

83. Nomakuchi S, Filippi L, Tojo S. Selective foraging behavior in nestprovisioning females of Parastrachia japonensis (Hemiptera: Cydnidae): Cues for preferred food. J Insect Behav. 1998;11:605-19.

84. Filippi L, Hironaka M, Nomakuchi S. Risk-sensitive decisions during nesting may increase maternal provisioning capacity in the subsocial shield bug Parastrachia japonensis. Ecol Entomol. 2002;27:152-62.

85. Honbo Y, Nakamura K. Effectiveness of parental care in the bug Elasmucha putoni Scott (Hemiptera: Acanthosomatidae). Jpn J Appl Entomol Zool. 1985;29:223-29.
86. Folmer O, Black M, Hoeh W, Lutz R, Vrijenhoek R. DNA primers for amplification of mitochondrial cytochrome coxidase subunit I from diverse metazoan invertebrates. Mol Mar Bio Biotechnol. 1994;3:294-99.

87. Simon C, Frati F, Beckenbach A, Crespi B, Liu H, Flook P. Evolution, weighting, and phylogenetic utility of mitochondrial gene sequences and a comparison of conserved polymerase chain reaction primers. Ann Entomol Soc Am. 1994:87:81-144.

88. Colgan DJ, McLauchlan A, Wilson GDF, Livingston SP, Edgecombe GD, Macaranas J, et al. Histone $\mathrm{H} 3$ and U2 snRNA DNA sequences and arthropod molecular evolution. Aust J Zool. 1998;46:419-37.

89. Barker SC, Whiting MF, Johnson KP, Murrell A. Phylogeny of lice (Insecta: Phthiraptera) inferred from small subunit rRNA. Zool Scr. 2003;32:407-14.

90. Larkin MA, Blackshields G, Brown NP, Chenna R, McGettigan PA, McWilliam $\mathrm{H}$, et al. Clustal W and Clustal X version 2.0. Bioinformatics. 2007;23:2947-8.

91. Yoshizawa K, Johnson KP. Phylogenetic position of Phthiraptera (Insecta: Paraneoptera) and elevated rate of evolution in mitochondrial $12 \mathrm{~S}$ and $16 \mathrm{~S}$ rDNA. Mol Phylogenet Evol. 2003;29:102-14.

92. Simmons MP. Independence of alignment and tree search. Mol Phylogenet Evol. 2004;31:874-79.

93. Swofford DL. PAUP*. phylogenetic analysis using parsimony (*and other methods). version 4. Sunderland: Sinauer Associates; 2002.

94. Darriba D, Taboada GL, Doallo R, Posada D. jModelTest 2: more models, new heuristics and parallel computing. Nat Methods. 2012;9:772.

95. Guindon S, Gascuel O. A simple, fast and accurate method to estimate large phylogenies by maximum-likelihood. Syst Biol. 2003;52:696-704.

96. Guindon S, Dufayard JF, Lefort V, Anisimova M, Hordijk W, Gascuei O. New algorithms and methods to estimate maximum-likelihood phylogenies: assessing the performance of PhyML 3.0. Syst Biol. 2010;59:307-21.

97. Nylander JAA. MrModeltest V2. Program distributed by the author: Evolutionary Biology Centre, Uppsala University, Uppsala, Sweden; 2004.

98. Ronquist F, Huelsenbeck JP. MrBayes 3: Bayesian phylogenetic inference under mixed models. Bioinformatics. 2003;19:1572-4.

99. Frost SW, Haber VR. A case of parental care in Heteroptera. Ann Entomol Soc Am. 1944;37:161-66.

100. Carvajal MA, Faúndez El. Revalidation of Ditomotarsus hyadesi Signoret, 1885 stat. rest. (Hemiptera: Heteroptera: Acanthosomatidae) with notes on its natural history. Biodivers Nat Hist. 2015;1:18-25.

101. Maddison WP, Maddison DR. Mesquite: a modular system for evolutionary analysis. Version 3.02. 2015. https://mesquiteproject.wikispaces.com/. (accessed January 2015).

102. Pagel M. The maximum likelihood approach to reconstructing ancestral character states of discrete characters on phylogenies. Syst Biol. 1999;48:612-22.

103. Pagel M. Detecting correlated evolution on phylogenies: a general method for the comparative analysis of discrete characters. Proc R Soc London B. 1994;255:37-45.

104. Maddison DR, Maddison WP. MacClade 4: Analysis of phylogeny and character evolution. Version 4.08a. 2005. http://macclade.org. (accessed January 2015).

105. Jones WA, McPherson JE. The first report of the occurrence of acanthosomatids in South Carolina. J Georgia Entomol Soc. 1980;15:286-89.

\section{Submit your next manuscript to BioMed Central and take full advantage of:}

- Convenient online submission

- Thorough peer review

- No space constraints or color figure charges

- Immediate publication on acceptance

- Inclusion in PubMed, CAS, Scopus and Google Scholar

- Research which is freely available for redistribution

Submit your manuscript at www.biomedcentral.com/submit

C) Biomed Central 